\title{
Development of an Advanced Motor Control System for Electric Vehicles
}

\begin{abstract}
Electric vehicles are considered as one of the most popular way to decrease the consumption of petroleum resources and reduce environmental pollutions. Motor control system is one of the most important part of electric vehicles. It includes power supply module, IGBT driver, digital signal processing (DSP) controller, protection adjustment module, and resolver to digital convertor. To implement the control strategies on motor control system, a lot of practical aspects need to be taken into accounts. It includes setup of the initial excitation current, consistency of current between motor and program code, over-modulation, field weakening control, current protection, and so on. In this paper, an induction motor control system for electric vehicles is developed based on DSP. The control strategy is based on the field-oriented control (FOC) and space vector pulse width modulation (SVPWM). Speed calculation, over-modulation, field weakening control, PI controller, and fault diagnosis are also applied in this DSP algorithm. As an industry product running on a real electric bus with a $100 \mathrm{~kW}$ induction motor, communication with vehicle control unit (VCU) by CAN bus, control system safety and PC software designed for lab experiments are also discussed. This paper focused on how to develop the advanced motor control system for electric vehicles for industrial application. The steady-state and transient performances of this motor control system are analyzed by both test-bench experiments and road experiments. Its performance is satisfactory when applied to the real electric vehicle.
\end{abstract}

\section{Introduction}

Recently, electric vehicles have been promoted as a practical platform for reducing environmental pollution and mitigating energy crisis. Vehicle control unit (VCU), motor control system (MCU), and battery management system (BMS) are the main control systems of electric vehicles. Other technologies of electric vehicle include the motor design, body and chassis design, battery design, and particularly the system-level design and optimization of electric motor drive systems [1, 2, 3].

Motor control system plays a very important role in driver safety and comfort. Induction motors (IMs) are widely used for electric vehicles due to their simple structure, good performance, and low cost $[4,5$, 6]. As for the control methods for IM, there are the V/F control, field oriented control (FOC), direct torque control (DTC) and some modern control methods, like model predictive control (MPC), fuzzy control, and neural networks. However, for industrial products of electric vehicles, FOC appears to be the most popular control strategy $[7,8]$.

Page 1 of 8
This paper is focused on how to develop the induction motor advanced control system for electric vehicles based on DSP. Apart from the implementation of FOC and SVPWM, some practical problems, such as current protection, over-modulation and field weakening control method are all discussed and the performance of final control strategy is verified on a real electric bus. This paper shows some aspects, which need to be taken into account when developing motor control methods on digital control chips, like DSP, for industrial application. It will do some help for applying new control methods like MPC on industrial motor to achieve better performance.

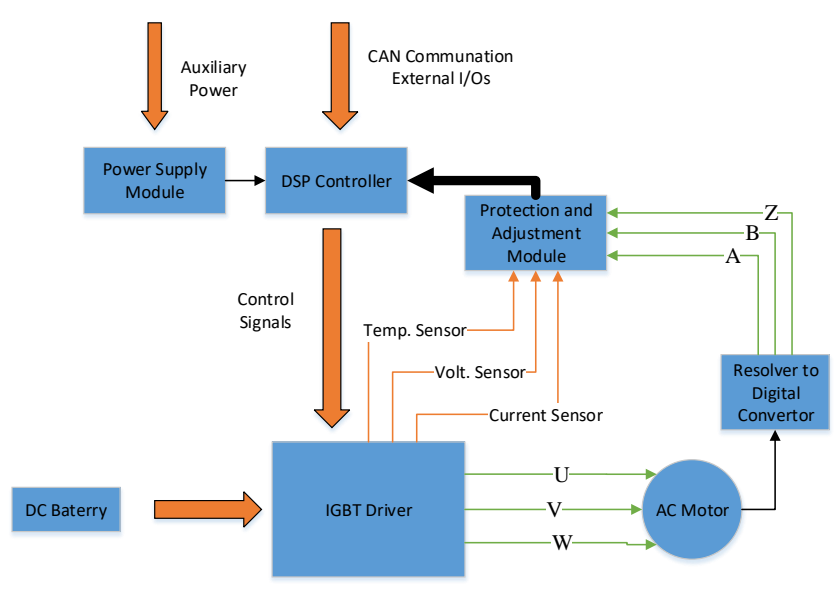

Figure 1. Diagram of motor control system.

\section{Construction of Motor Control System}

\section{Basic Diagram of the System}

Figure 1 shows the diagram of the motor control system. The motor control system of electric vehicle includes the power supply module, IGBT driver, DSP controller, protection and adjustment module, and resolver to digital convertor. The power source of this electric bus is a $650 \mathrm{~V}$ battery set. It supplies voltage to IGBT driver and converts it to various voltage power source as required for other parts of motor control system. IGBT module receives instructions from DSP controller and produces balanced three phase voltage (U V W) to drive the induction motor. It also collects the temperature, voltage and current signals and then transfers them to the DSP controller via protection and adjustment module. Resolver to digital convertor detects the motor speed with direction and then produces three corresponding signals (A B Z) and transfers them to DSP for speed 
calculation. Signals A and B are two square wave signals with 90 electrical degrees out of phase, which contain the data of motor speed. Signal Z is the signal of speed direction. DSP controller communicates with vehicle controller using CAN bus. It produces the motor drive PWM signals based on FOC and SVPWM algorithm and sends them to IGBT driver and thus drives motors. The DSP TMS320F28335 is used in the test-bench experiments and a real bus motor control system. Its high performance is quite appropriate for motor control system [9].

\section{Hardware of the System}

\section{Basic Requirements}

1. The hardware system has excellent hardware safety. It has the capability of measuring bus voltage, phase current and system temperature. It has quick responds to over voltage error, over current error, over temperature error, phase lost and other running errors. When error happens, it will turn off IGBT and decrease the motor speed to stop the electric vehicle.

2. The hardware system has good electromagnetic compatibility (EMC). It has a nice control of electromagnetic interference (EMI) so that unwanted effects are prevented when the electric vehicle is running in a complex condition.

3. It supports CAN bus and 485 ports. The system is composed of several functional packages and easily to be adjusted to fit for other systems.

4. The system is stable for complex environments. It survives between $-40^{\circ} \mathrm{C}$ and $125^{\circ} \mathrm{C}$ and its shell is waterproof.

\section{CPU Module}

TMS320F28335 is a 32-bit floating-point processor, which is produced by Texas Instruments (TI). It has six enhanced PWM modules, two enhanced quadrature encoder pulse (QEP) modules, one Enhanced analog-to-digital converter (ADC) module with sixteen channels, two enhanced controller area network (eCAN) modules, three serial communications interface modules, one serial peripheral interface (SPI) module and abundant on-chip memory [9]. It is Harvard bus architecture and its operating frequency is up to $150 \mathrm{MHz}$. Its high performance is quite well for the motor control system.

\section{Power Supply Module}

Battery voltage is transformed to $15 \mathrm{~V}, 24 \mathrm{~V}$ and $5 \mathrm{~V}$ system voltage by specialized convertor. F28335 needs $3.3 \mathrm{~V}$ as I/O output voltage and $1.8 \mathrm{~V}$ as digital parts supply voltage. The voltage is acquired by voltage management chip AZ1117D. AD convertor reference voltage is $1.25 \mathrm{~V}$ and it is obtained by PWM output of DSP.

\section{IGBT Driver}

The IGBT driver is designed on a separate PCB board. This kind of design is convenient for adjusting circuit for power need of different system. The FF400RKE3 is used as IGBT and M57962AL is used for IGBT driver. As for IGBT FF400RKE3, DC forward current is 400A, gate threshold voltage is $5.8 \mathrm{~V}$, turn-on delay time is $0.25 \mathrm{us}$, turn-off delay time is 0.5 us. IGBT driver M57962AL has two voltage supply topology, its output voltage works at $15 \mathrm{~V}$ for IGBT gate.

\section{Phase Current and Voltage Measurement}

Phase current is acquired by current transducer HAT500-S from LEM. Its supply voltage is $\pm 15 \mathrm{~V}$ and it has accuracy about $1 \%$, which is good enough for phase current measurement. Voltage is acquired by ADC of DSP through adjustment circuit from phase current. The max value of ADC for current and voltage are 1273.5A and $963 \mathrm{~V}$ respectively in this system.

\section{Speed Measurement}

The speed is measured by QEP of DSP and resolver to digital converter AU6802. Smart-coder AU6802 converts the electrical information, which is corresponding to a mechanical rotational angle of the resolver, to a digital signal and send it to DSP. The output of AU6802 could be set as pulse output and parallel absolute output. Parallel output has two mode, parallel bus interface mode and parallel I/O interface mode. In this system, it is set as pulse output mode. QEP module supports low speed measurement with capture unit and high speed measurement with a 32-bit unit timer.

\section{Implementation of Algorithm}

\section{Scheme of FOC for AC IM}

Figure 2 is the basic scheme of FOC for AC IM. Some function blocks are designed by using some modules from TI library. These function blocks are easy to update and comfortable to add new functions, which make them portable to be used in other systems as well. Each macro function block has its parameters, input and output. When running the algorithm on DSP, these blocks are tested level by level [10]. The results are tested at each level to ensure that all these functions are running well as required.

IPARK MACRO is the inverse Park transformation and PARK MACRO is the Park transformation. CLARK MACRO is the Clark transformation. SVGEN MACRO includes inverse Clark transformation and SVPWM [11]. There are two zero vectors $\left(\mathrm{U}_{0}\right.$, $\left.\mathrm{U}_{7}\right)$ and six basic vectors $\left(\mathrm{U}_{1}-\mathrm{U}_{6}\right)$ in the three-phase inverter as shown in Figure 3.

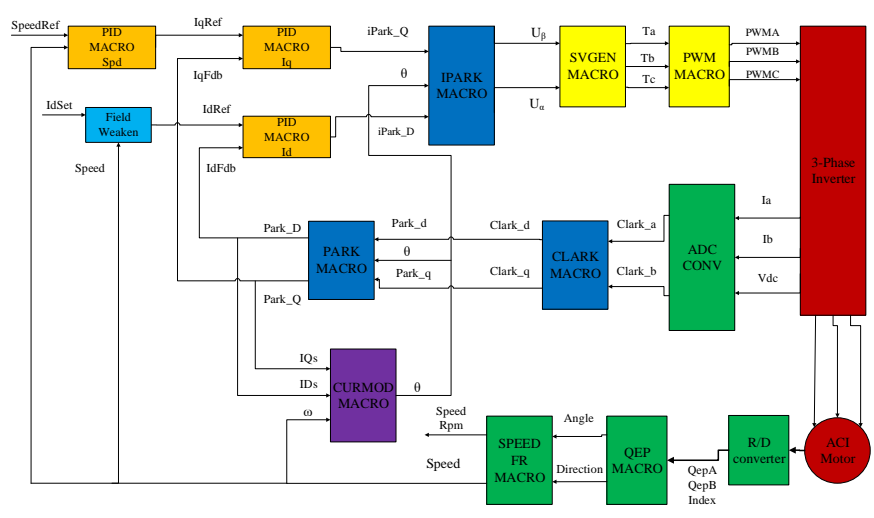

Figure 2. Scheme of FOC based on DSP. 
Giving $U_{\alpha}$ and $U_{\beta}$, one can have a $U_{\text {ref }}$ as input, which can be equally obtained from two of the six basic vectors. In the DSP program, it is needed to acquire the PWM durations $\mathrm{T}_{1}$ and $\mathrm{T}_{2}$ of the two corresponding basic vectors. Therefore, one has to know in which sector the $U_{r e f}$ is located for acquiring the correct duration. To find out the correct sector, three variables, $V_{r e f 1}, V_{r e f 2}, V_{r e f 3}$ are used.

$$
\begin{aligned}
& V_{\text {ref } 1}=U_{\beta} \\
& V_{\text {ref } 2}=\frac{-U_{\beta}+\sqrt{3} U_{\alpha}}{2} \\
& V_{\text {ref } 3}=\frac{-U_{\beta}-\sqrt{3} U_{\alpha}}{2}
\end{aligned}
$$

If $V_{\text {ref } 1}>0$ then a $=1$, else $a=0$. If $V_{\text {ref } 2}>0$ then $\mathrm{b}=1$, else $\mathrm{b}=0$. If $V_{\text {ref } 3}>0$ then $\mathrm{c}=1$, else $\mathrm{c}=0$;

The sector is defined as, sector $=4 * c+2 * b+a$. According to this, the correct sector, in which the $U_{r e f}$ is located, can be worked out. As to the duration, it can be found out that there are only three basic values for calculating in all the possible occasions. Variables $\mathrm{X}, \mathrm{Y}, \mathrm{Z}$ are used here to calculate the final duration, where

$$
\begin{aligned}
& \mathrm{X}=U_{\beta} \\
& \mathrm{Y}=\frac{1}{2}\left(\sqrt{3} U_{\alpha}+U_{\beta}\right) \\
& \mathrm{Z}=\frac{1}{2}\left(-\sqrt{3} U_{\alpha}+U_{\beta}\right)
\end{aligned}
$$

Then the duration table can be obtained as table 1 shows. As implementation is based on DSP, one should use the related registers to get the trigger value and thus one can get the expected PWM for motor drive [7].

QEP MACRO and SPEED FR MACRO are the parts of calculation of motor speed. CURMOD MACRO is the current module. It uses the motor speed to calculate the electrical angle, which is needed for Park transformation and inverse Park transformation. PID MACRO is the PID control unit. It plays a great role in the transient and steadystate performance of the control system.

\begin{tabular}{|c|c|c|c|c|c|c|}
\hline Sector & 3 & 1 & 5 & 4 & 6 & 2 \\
\hline Vector & $\begin{array}{l}\text { U1, } \\
\text { U2 }\end{array}$ & $\begin{array}{l}\text { U3, } \\
\text { U2 }\end{array}$ & $\begin{array}{l}\text { U3, } \\
\text { U4 }\end{array}$ & $\begin{array}{l}\text { U5, } \\
\text { U4 }\end{array}$ & $\begin{array}{l}\text { U5, } \\
\text { U6 }\end{array}$ & $\begin{array}{l}\text { U1, } \\
\text { U6 }\end{array}$ \\
\hline $\mathrm{t} 1$ & $-Z$ & $\mathrm{Z}$ & $\mathrm{X}$ & $-X$ & $-Y$ & $\mathrm{Y}$ \\
\hline $\mathrm{t} 2$ & $X$ & Y & $-Y$ & $\mathrm{Z}$ & $-Z$ & $-X$ \\
\hline
\end{tabular}

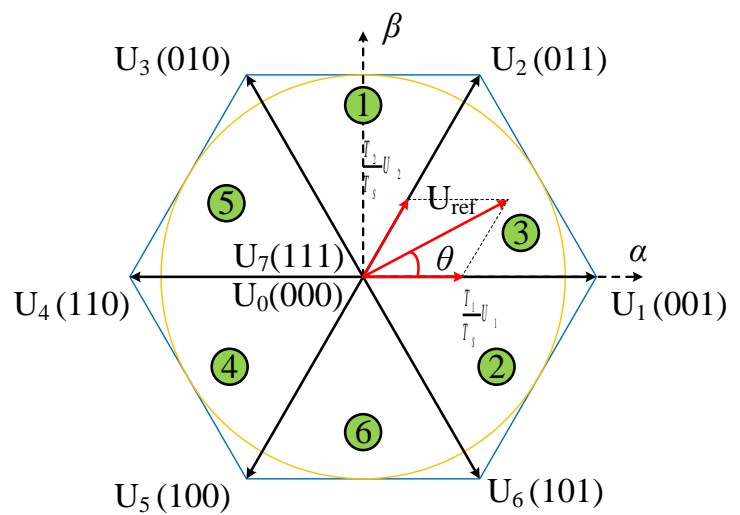

Figure 3. SVPWM scheme: $\mathrm{U}_{1}-\mathrm{U}_{6}$ are the basic vectors, $\mathrm{U}_{0}$ and $\mathrm{U}_{7}$ are the zero vectors, and $T_{s}$ is the control period.

Page 3 of 8
Table 1. Duration select table

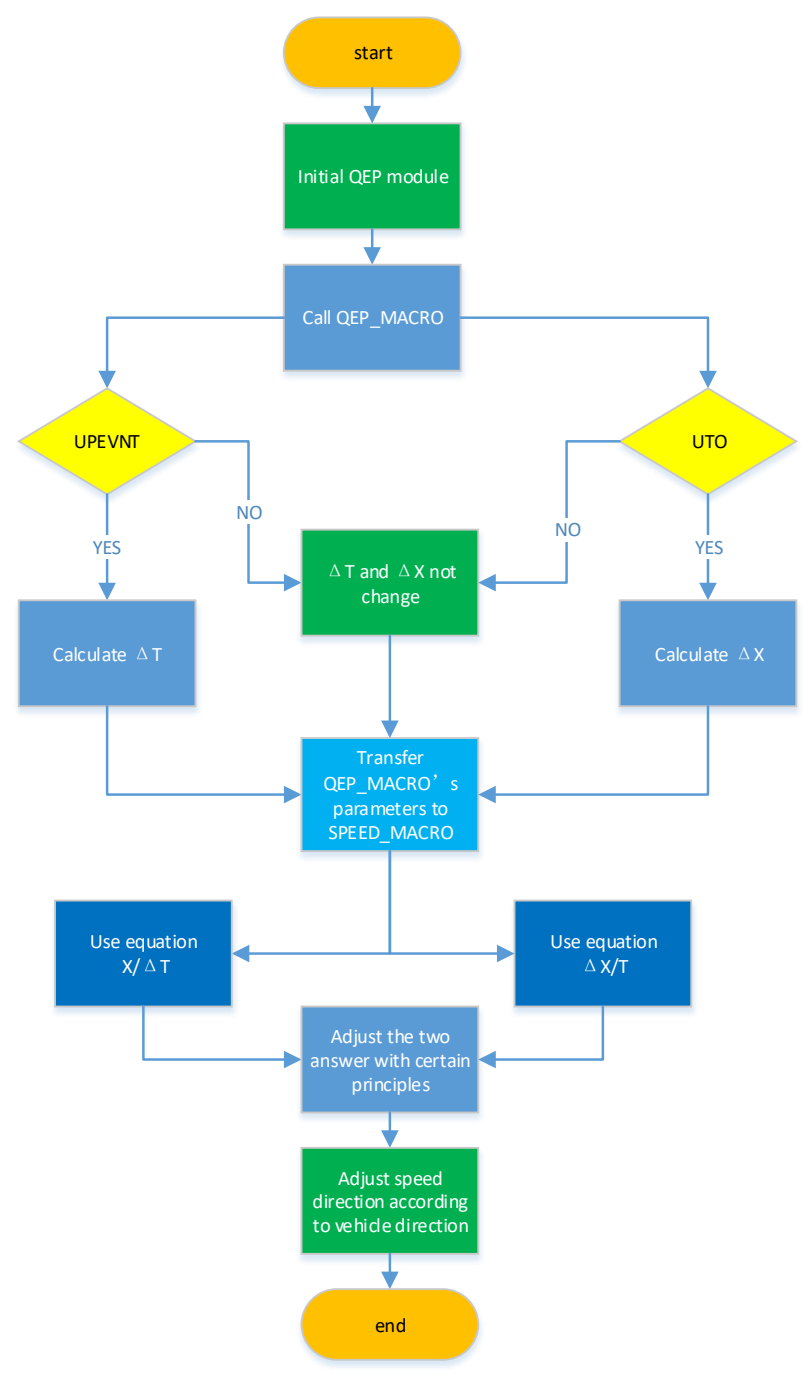

Figure 4. Speed calculation flow diagram

\section{Speed Calculation Algorithm}

Speed measurement is a very important value for the FOC algorithm. The current module needs the value of speed to estimate the flux angle while Park transformation and Clark transformation need the 
flux angle to do calculation. The speed measurement equations are shown as (7) and (8).

$$
\begin{aligned}
& \mathrm{v}_{\mathrm{L}}(\mathrm{k})=\frac{X}{t(k)-t(k-1)}=\frac{X}{\Delta T} \\
& \mathrm{v}_{H}(\mathrm{k})=\frac{x(k)-x(k-1)}{T}=\frac{\Delta X}{T}
\end{aligned}
$$

where

$\mathrm{X}$ : Unit position defined by integer multiple of quadrature edges $\Delta \mathrm{T}$ : Elapsed time between unit position events

$\Delta \mathrm{x}$ : Incremental position movement in unit time

$\mathrm{T}$ : Unit time

Equation (7) is used for low speed measurement and equation (8) is for high speed measurement. Final speed used in algorithm is derived from a combination of this two methods. Speed calculation flow is shown as figure 4 .

\section{DSP Algorithm}

The FOC is implemented on DSP and it is the major part of the motor control system for electric vehicle. Its control frequency is actually based on the PWM interrupt service frequency. In addition to the main FOC algorithm, over-modulation, field weakening control, the system protection, error detection, communication with PC and vehicle control unit, and other aspects, are also considered [12].

The main program flow diagram is shown in Figure 5. When the motor control system starts, the system clock and GPIO are initialized by function DeviceInit(). MemCopy() moves MainISR to

RAM from flash to save running time. GetSysPara() is the function of reading parameters from FRAM, which is based on protocol $\mathrm{I}^{2} \mathrm{C}$.

These parameters include the motor parameters and some parameters for communication between DSP and PC. Three tasks are always running in the background loop. The FOC control algorithm runs in PWM interruption service function program (PWM_ISR) and FAULT_ISR deals with all the error diagnose work. When the system detects some errors in running state, the protection action will be triggered and the motor speed will decelerate gradually and then the motor will shut down in the end. Errors will be uploaded to the vehicle control unit or PC for further analysis. The PWMISR program flow diagram is shown in Figure 6. The modules mentioned in the FOC scheme are used in this program. PWM signals are produced as required by these program.

As this development is based on DSP and used for electric vehicles, some work about electric vehicle also needs to be accomplished. Three tasks in background loop are used to deal with the following problems. AD sampling, temperature and battery voltage monitor, current protection and collecting data for analysis are running in task A. Communications with PC and vehicle control unit are operating in task B and task C. The CAN module of DSP is used to perform this communication. When transferring data by CAN, the protocol with each terminal equipment needs to be made. The driver's instructions, like starting moving, stopping moving, accelerating the speed, and changing gears, are all sent by CAN in these tasks.

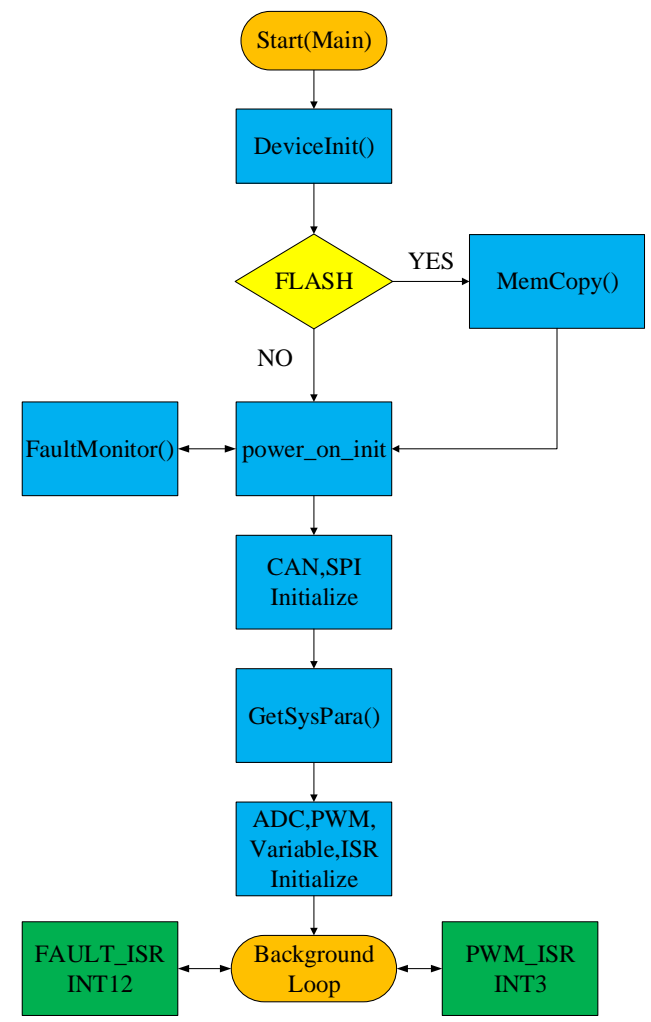

Figure 5. Main DSP program flow diagram.
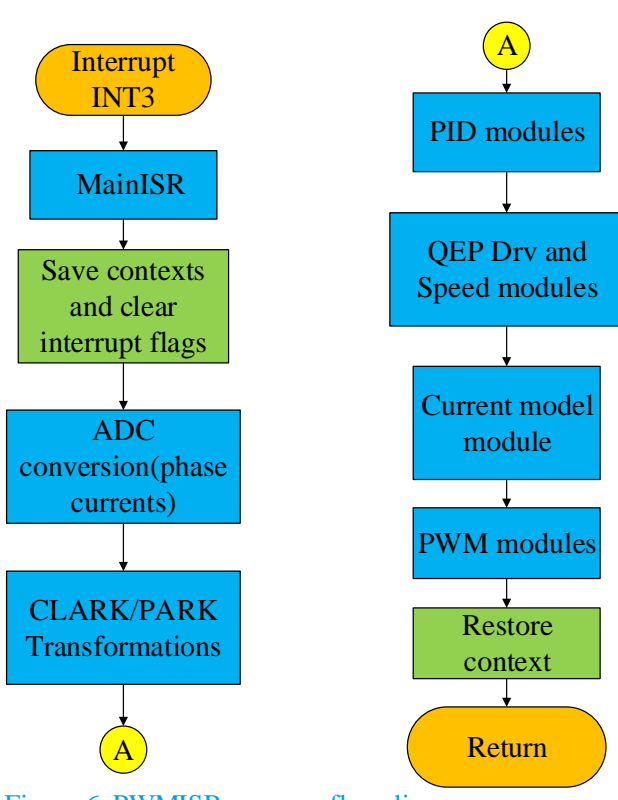

Figure 6. PWMISR program flow diagram

\section{Practical Problems}

The motor control system is designed for real electric vehicle, some practical problems of development need to be considered. 


\section{Initial Excitation Current}

The flux is calculated on $\mathrm{I}_{\mathrm{sd}}$ and torque is related to $\mathrm{I}_{\mathrm{sq}}$. For convenience, $\mathrm{I}_{d}$ presents $\mathrm{I}_{s d}$ and $\mathrm{I}_{q}$ presents $\mathrm{I}_{s q}$ in the flowing part for implementing on electric vehicle. $I_{q}$ is an important parameter for the driver's acceleration paddle. $\mathrm{I}_{\mathrm{d}}$ is not controlled by the driver and thus it should be set up as initial value in the program. The no-load current is $\mathrm{I} 0$, which is a constant of the motor. Therefore, it is requested to decide the correct $\mathrm{I}_{\mathrm{d}}$ from $\mathrm{I}_{0}$.

The inverse Park transformation is:

$$
\left[\begin{array}{l}
I_{\alpha} \\
I_{\beta}
\end{array}\right]=\left[\begin{array}{cc}
\cos \theta & -\sin \theta \\
\sin \theta & \cos \theta
\end{array}\right]\left[\begin{array}{l}
I_{d} \\
I_{q}
\end{array}\right]
$$

Where $I_{d}, I_{q}$ are the currents in rotating coordinates frame and $I_{\alpha}, I_{\beta}$ are the currents in stationary coordinates frame, and $\theta$ is the electrical angle, respectively.

Set $I_{q}=0$, one can have

$$
\begin{aligned}
& I_{\alpha}=\cos \theta * I_{d} \\
& I_{\beta}=\sin \theta * I_{d}
\end{aligned}
$$

The Clark transformation is:

$$
\left[\begin{array}{l}
\mathrm{I}_{a} \\
I_{b} \\
I_{c}
\end{array}\right]=\left[\begin{array}{cc}
1 & 0 \\
-\frac{1}{2} & \frac{\sqrt{3}}{2} \\
-\frac{1}{2} & -\frac{\sqrt{3}}{2}
\end{array}\right]\left[\begin{array}{l}
I_{\alpha} \\
I_{\beta}
\end{array}\right]
$$

where $I_{a}, I_{b}, I_{c}$ are the currents in the three phase frame.

Combining (12) with (10) and (11), one can have

$$
\begin{aligned}
& I_{\mathrm{a}}=\cos \theta * I_{d} \\
& I_{\mathrm{b}}=\cos \left(\theta-120^{\circ}\right) * I_{d} \\
& I_{\mathrm{c}}=\cos \left(\theta+120^{\circ}\right) * I_{d}
\end{aligned}
$$

The RMS current of $I_{\mathrm{a}}$ equals $I_{d} / \sqrt{2}$, and thus

$$
I_{d}=\sqrt{2} I_{0}
$$

According to (16), the correct excitation current can be confirmed for the system based on motor parameters.

\section{Current Consistency of Program and Motor}

In the DSP program, the three phase currents of motor, Ia, Ib and Ic, can be used and the program produces duration of PWM to control the current. The motor has three phases, namely, U, V and W. When producing the PWM duration, the correct basic vector is used, which is directly related to the three physical bridges of IGBT. The phase current data are obtained by AD converter. The correct corresponding feedback current is needed to calculate the error as input of PID controller.

Page 5 of 8
1. Set $\mathrm{Id}=1$, and $\mathrm{Iq}=0, \theta=0$, according to inverse Park transformation and Clark transformation, the voltage vector is around $\mathrm{U}_{1}(001)$. Check the motor's three phase output, U V W. The phase with longest time of high level means that it is the feedback of Ia in the program. Figure 7 shows that phase U has the longest high level voltage, so it is connected to phase A in program. Notice that, when doing experiment, $\mathrm{Id}=0.95$ and Iq $=0.05$ was set for safety, which doesn't affect the results and conclusions.

2. Set $I d=0$, and $I q=1$, which means that the voltage vector is combination of $U_{3}(010)$ and $U_{2}(011)$. Check the output of $U \mathrm{~V}$ $\mathrm{W}$. The phase with longest time of high level means the feedback of Ib and that with the shortest time of high level means the feedback of Ic. Figure 8 shows that phase $\mathrm{V}$ has the longest high level voltage, so it is connected to phase B in program. Phase $\mathrm{W}$ has the shortest time of high level so it is connected to phase $\mathrm{C}$ in program.

According to these experiments, Ia, Ib, and Ic in the program can match with the physical motor phases $\mathrm{U}, \mathrm{V}$, and $\mathrm{W}$. In this case, motor phase $\mathrm{U}$ is connected to program phase $\mathrm{A}, \mathrm{V}$ is connected to phase $\mathrm{B}$, and $\mathrm{W}$ is connected to phase $\mathrm{C}$. As for the hardware, motor phase $\mathrm{U}$ is connected to ADC channel 2, $\mathrm{V}$ is connected to ADC channel 0 , and $\mathrm{W}$ is connected to ADC channel 1 . So phase A, B, C should use ADC channel 2, 0, 1, separately, for correct physical connection. If they do not match, the performance of torque and speed would be very bad.

\section{Current Zero Drift Compensation}

Before the main algorithm starts, OffsetISR interruption service function runs first. Phase current A, B, C are calculated for 500 times and the average value for each phase current is taken as its offset current separately for compensation in OffsetISR program. Once this job is done, the PWM service entrance changes to mainISR for the main algorithm. Phase current is compensated by the offset current calculated in OffsetISR, so that the current zero drift is fixed.

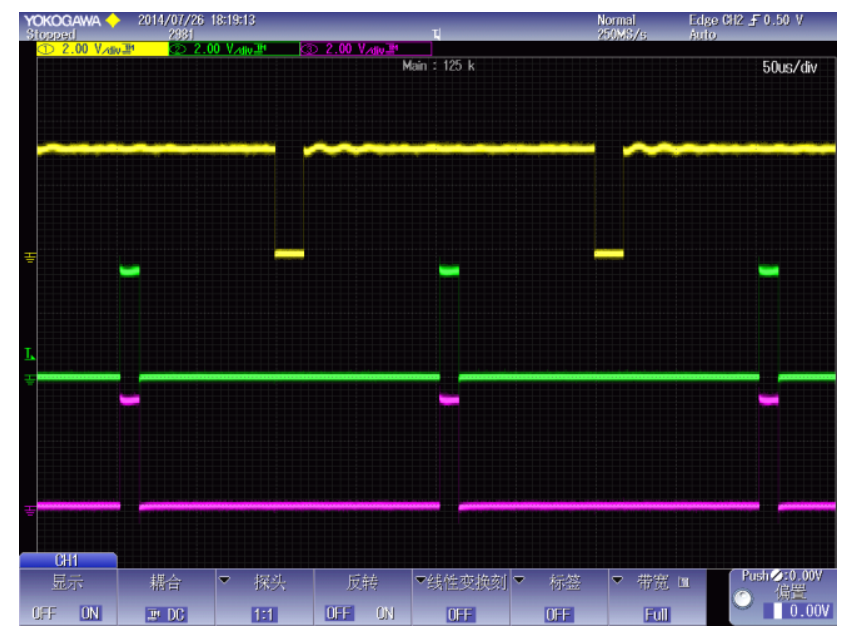

Figure 7. $I d=0.95, I q=0.05$, yellow signal- phase $U$, green - phase $V$, pink phase $\mathrm{W}$. 


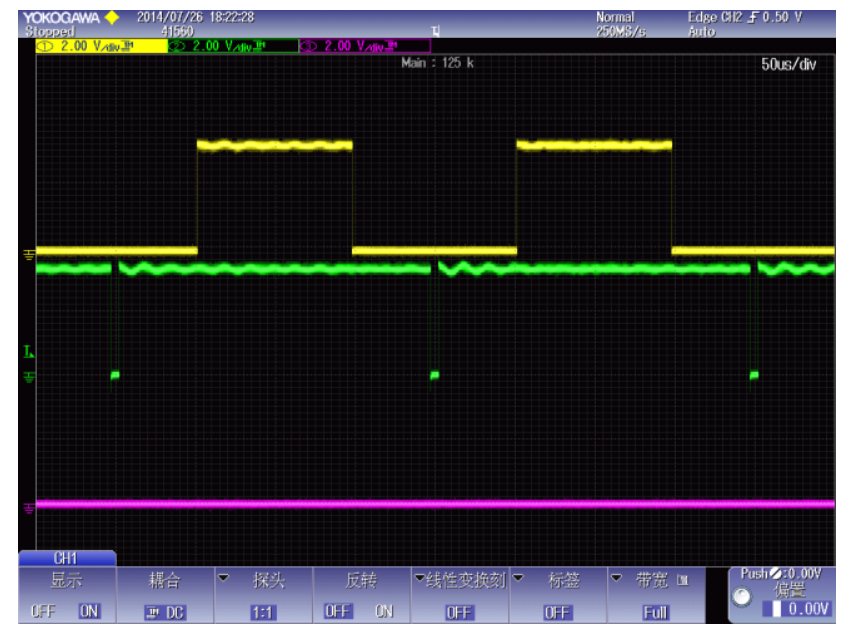

Figure $8 . \mathrm{Iq}=0.95, \mathrm{Id}=0.05$, yellow signal - phase $\mathrm{U}$, green - phase $\mathrm{V}$, pink phase W.

\section{Over Modulation}

When the values of $\mathrm{I}_{\mathrm{d}}$ and $\mathrm{I}_{\mathrm{q}}$ are given, the $\mathrm{U}_{\text {ref }}$ is settled as well. According to the principle of SVPWM, the duration of PWM as $\mathrm{T}_{1}$ and $T_{2}$ can be obtained. However, improper $\mathrm{U}_{\text {ref }}$ could lead to the sum of $T_{1}$ and $T_{2}$ of more than unit 1 . In the program, the unit 1 is settled by control period. Therefore, when $\mathrm{T}_{1}$ or $\mathrm{T}_{2}$ is not correct, the distortion of current and low power efficiency may happen. To avoid this situation, an easy but proper way is proposed. That is to scale down $T_{1}$ and $T_{2}$ to make their sum equal to unit 1 . The logic diagram is shown in Figure 9.

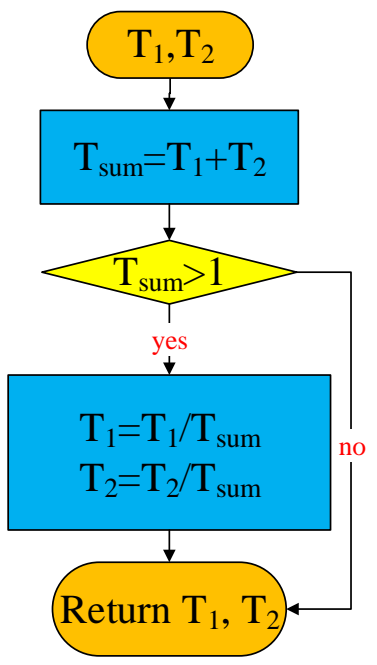

Figure 9. Over-modulation logic diagram

\section{Field Weakening Control Strategy}

The system power will reach its rated value when the motor reaches its rated speed. To achieve higher speed, the excitation current needs to be reduced. In this project, a variable $x_{m}$ is used to weaken the flux. It can be written as the form (17) shown, where $\mathrm{v}$ is speed of the motor.

Page 6 of 8

$$
x_{m}=f\left(v^{-1}, v^{-2}\right)
$$

In this platform, $x_{m}$ is chosen as equation (18)

$$
x_{m}= \begin{cases}0.83 * v^{-1} * v_{m} & \text { if } v \leq 1.2 * v_{m} \\ v^{-2} * v_{m}^{2} & \text { if } v>1.2 * v_{m}\end{cases}
$$

Where $v_{m}$ is the rated speed, which equals to $1000 \mathrm{rpm}$ in this project.

Figure 10 is a situation when $x_{m}$ is not appropriate, which results in speed getting capped and staying in its highest speed after reaching rated speed. Speed can increase well in Figure 11 while $x_{m}$ works referring to equation (18). In this two figures, for current variables, Yaxis has a bias of 12735 and the value it shows is ten times the real value of Id, Iq, respectively. The speed value is shown as it is. In figure 10 , motor speed couldn't increase after it reaches around rated speed while motor speed in figure 11 could, which verifies the importance of field weakening control strategy. A good strategy could lead a better speed range in real electric vehicles.

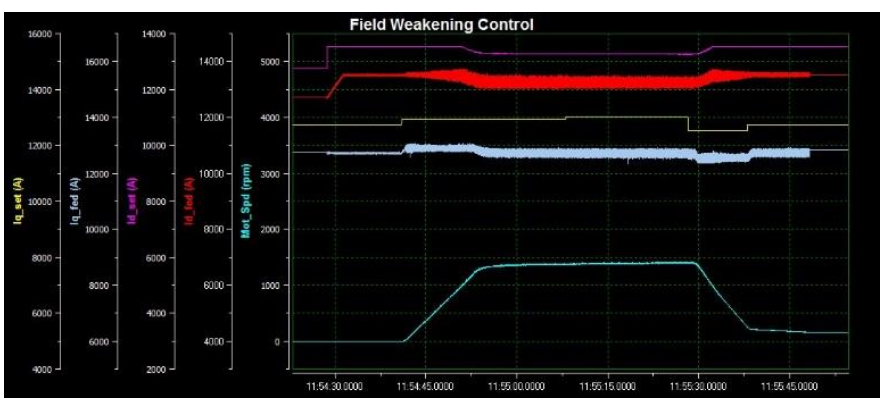

Figure 10. Speed and $\mathrm{I}_{\mathrm{d}}$ responses versus changing $\mathrm{I}_{\mathrm{q}}$ when $x_{m}$ is not appropriate

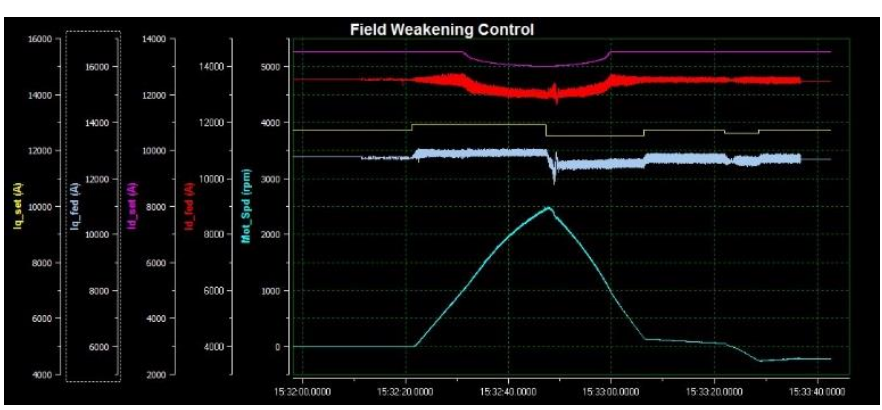

Figure 11. Speed and $\mathrm{I}_{\mathrm{d}}$ responses versus changing $\mathrm{I}_{\mathrm{q}}$ when $x_{m}$ is appropriate

\section{PC Software}

A PC software is designed for the experiments of motor control system. It has function of downloading motor parameters to DSP, start running, stop running, monitor of program parameters and some other functions. CAN communication protocol between PC software and DSP is designed as needed.

\section{Experimental Results and Discussions}

Figure 12 shows the experiment setup, with the voltage source, dynamometer, target induction motor, current sensors, oscilloscope, etc. The parameters [13] of target motor is listed in Table 2. 
The experiment is carried out on a towing electric motor test bench. When the experiments are conducted for testing speed performance, the opposite motor will offer a fix torque. When the experiments are conducted for torque performance, the opposite motor will offer a fix speed. By doing these, the transient performance and steady state performance can be achieved.

When the electric vehicle driver gives an acceleration signal, it will be finally transferred to an $I_{q}$ value by the motor control system and then carried out to obtain a demanded torque and the speed of vehicle increases as a consequence. For experiment at lab, the motor control system can be connected with PC and the instruction is given by software in PC. The load motor can be set to run at a fix speed and then different $I_{q}$ is set to acquire the torque performance of target motor. The responses of torque regarding to different input values of $I_{q}$, is shown in Figure 13 and the torque ripples around rated value $(1000 \mathrm{Nm})$ is shown in Figure 14. The voltage and phase current is shown in figure 15 and figure 16. Voltage doesn't change much during change of $\mathrm{I}_{\mathrm{q}}$. Phase current increases with the increase of $\mathrm{I}_{\mathrm{q}}$ and these three phase current is balanced all the time as Figure 16 shows. In Figure 13, $\mathrm{I}_{\mathrm{q}}$ is increased step by step, while the speed is fixed by the opposite motor as a load. The transient response is satisfactory and its torque is very stable with a ripple of under $\pm 3 \%$, which is normally considered as a good performance for electric bus.

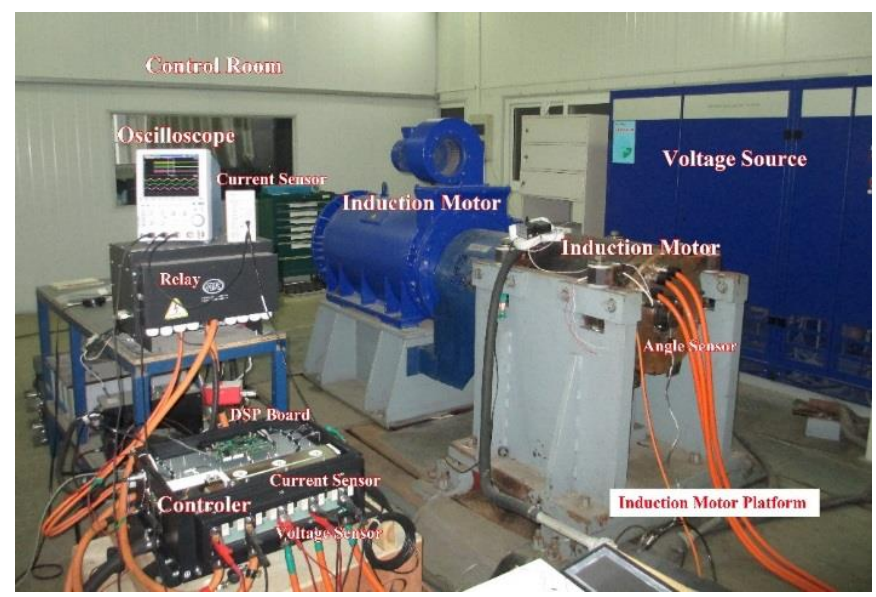

Figure 12. Experiment setup.

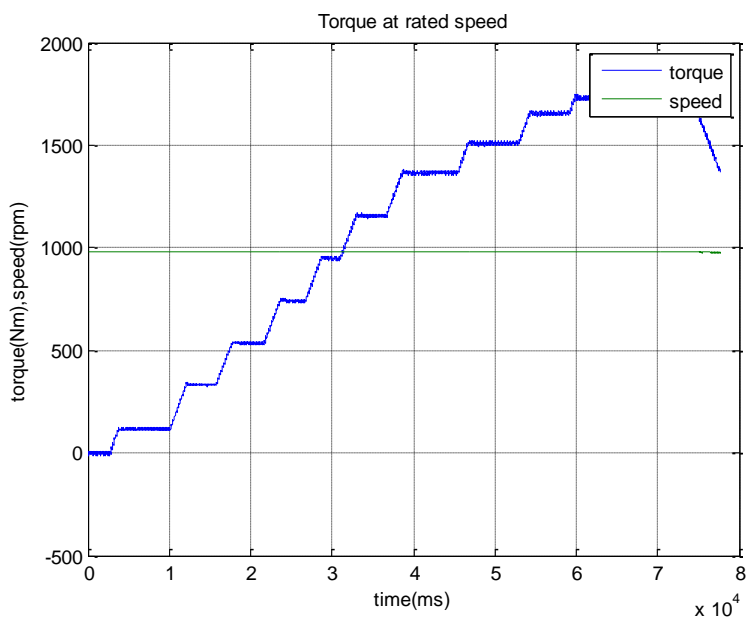

Figure 13. Torque responses versus changing $\mathrm{I}_{\mathrm{q}}$

Page 7 of 8

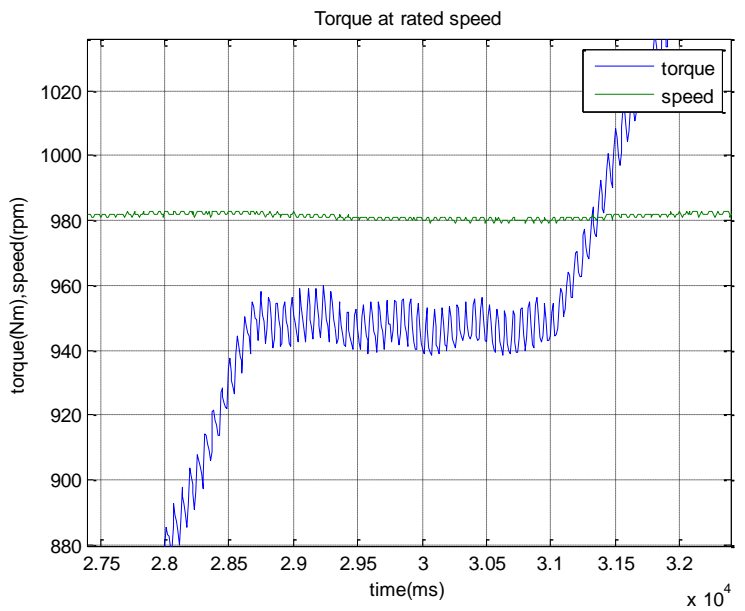

Figure 14. Ripples at rated torque.

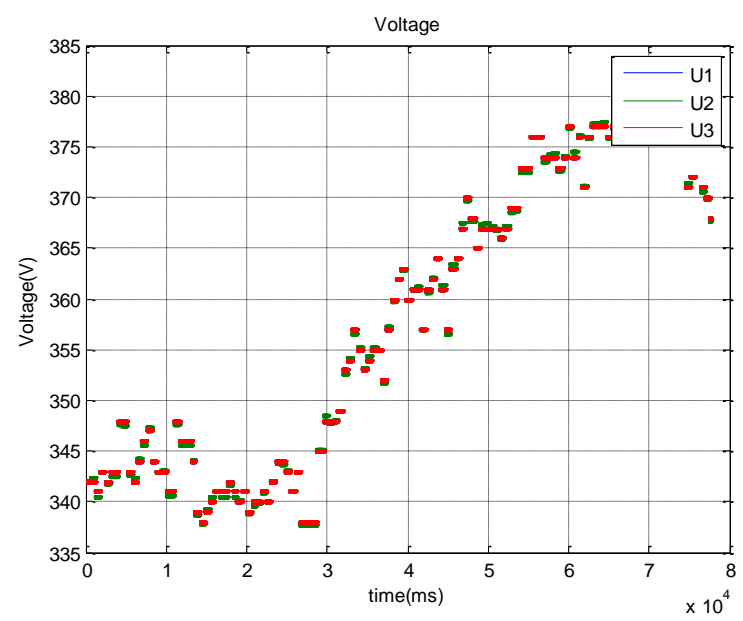

Figure 15. Voltage responses versus changing $I_{q}$

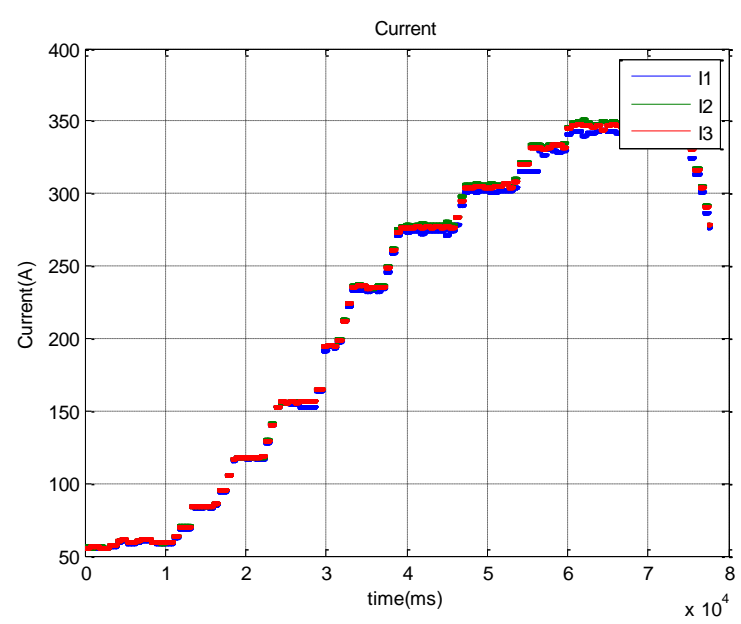

Figure 16. Phase current responses versus changing $I_{q}$ 
Table 2. Motor parameters

\begin{tabular}{|l|l|l|}
\hline Motor Parameters & Value & Unit \\
\hline Rated power & 100 & $\mathrm{~kW}$ \\
\hline Rated voltage & 350 & $\mathrm{~V}$ \\
\hline Rated current & 178 & $\mathrm{~A}$ \\
\hline Rated speed & 1000 & $\mathrm{rpm}$ \\
\hline Number of pole pairs & 3 & \\
\hline Rr & 0.01 & $\Omega$ \\
\hline Lr & 7.5 & $\mathrm{mH}$ \\
\hline Rs & 2400 & $\mathrm{Nm}$ \\
\hline Pak power & 0.019 & $\mathrm{~kW}$ \\
\hline & 10.9 & \\
\hline
\end{tabular}

\section{Summary}

This paper introduces the development of an advanced motor control system for electric vehicles based on DSP. Some problems of development as industrial product are put forward and some corresponding solutions are also proposed. Its torque responds are fast and stable. Its performance is verified by experimental results with a $100 \mathrm{~kW}$ induction motor, which are satisfactory. This motor control system is easy to match for different induction motors and thus it can be widely used for electric vehicles.

\section{References}

1. Xu, W., Zhu, J., Guo, Y., Wang, S. et al., "Survey on Electrical Machines in Electrical Vehicles," Paper presented at the 2009 International Conference on Applied Superconductivity and Electromagnetic Devices, ASEMD 2009, September 25, 2009 September 27, 2009, Chengdu, China, 2009.

2. Lei, G., Wang, T., Guo, Y., Zhu, J. et al., "System-Level Design Optimization Method for Electrical Drive Systems-Robust Approach," Ieee Transactions on Industrial Electronics 62, no. 8 (Aug 2015): 4702-13, doi: 10.1109/TIE.2015.2404305

3. Lei, G., Wang, T., Guo, Y., Zhu, J. et al., "System-Level Design Optimization Methods for Electrical Drive Systems: Deterministic Approach," Ieee Transactions on Industrial
Electronics 61, no. 12 (Dec 2014): 6591-602, doi:10.1109/TIE.2014.2321338

4. Xu, W., Zhu, J., Tan, L., Guo, Y. et al., "Optimal Design of a Linear Induction Motor Applied in Transportation," 2009 Ieee International Conference on Industrial Technology, Vols 1-3 (2009): 318.

5. Guo, Y., Xu, W., Zhu, J., Lu, H. et al., "Design and Analysis of a Linear Induction Motor for a Prototype Hts Maglev Transportation System," Paper presented at the 2009 International Conference on Applied Superconductivity and Electromagnetic Devices, ASEMD 2009, September 25, 2009 September 27, 2009, Chengdu, China, 2009.

6. Xu, W., Zhu, J., Zhang, Y., Li, Y. et al., “An Improved Equivalent Circuit Model of a Single-Sided Linear Induction Motor," Ieee Transactions on Vehicular Technology 59, no. 5 (Jun 2010): 2277-89, doi:10.1109/Tvt.2010.2043862.

7. Casadei, D., Profumo, F., Serra, G., and Tani, A., "Foc and Dtc: Two Viable Schemes for Induction Motors Torque Control," Ieee Transactions on Power Electronics 17, no. 5 (Sep 2002): 779-87, doi:10.1109/TPEL.2002.802183

8. Bose, B, Simoes, M., Crecelius, D., Rajashekara, K. et al., "Speed Sensorless Hybrid Vector Controlled Induction Motor Drive," Ias '95 - Conference Record of the 1995 Ieee Industry Applications Conference/Thirtieth Ias Annual Meeting, Vols 1-3 (1995): 137-43, doi: 10.1109/IAS.1995.530294

9. Instruments T. TMS320F28335, Digital Signal Controllers (DSCs), Data Manual, Literature Number: SPRS439I, 2007.

10. Akin, B. and Bhardwaj, M. "Sensored Field Oriented Control of 3-phase Induction Motors," Texas Instrument Guide, 2013

11. Instruments, Texas, TMS320x2833x, 2823x enhanced pulse width modulator (ePWM) module reference guide (literature number: SPRUG04A). 2009.

12. Men, X., Guo, Y., Wu, G., Shi, C. et al., "Implementation of a Motor Control System for Electric Bus Based on DSP." Paper presented at the 20th International Conference on Electrical Machines and Systems, ICEMS 2017, August 11, 2017 - August 14, 2017, Sydney, NSW, Australia, 2017, doi:2017.10.1109/icems.2017.8056504.

13. Khan, A. and Kress, M., "Identification of Permanent Magnet Synchronous Motor Parameters," SAE Technical Paper 201701-1237, 2017, doi:10.4271/2017-01-1237.

\section{Contact Information}

Xiaojin Men

xjmen@mail.ustc.edu.cn

Affiliations:

1. University of Science and Technology of China (USTC)

2. China Automotive Technology and Research Centre (CATARC) 